\title{
Mechanic and Enneroy
}

\section{Bruno Kenta Sato}

Graduando em Engenharia Mecânica

Universidade Estadual Paulista Júlio de Mesquita

Filho - Campus de Bauru

Departamento de Engenharia Mecânica

Bauru - São Paulo - Brasil

brunokentasato@gmail.com

\section{Alan Rodrigo de Sales}

Doutorando em Engenharia Mecânica

Universidade Estadual Paulista Júlio de Mesquita

Filho - Campus de Bauru

Departamento de Engenharia Mecânica

Bauru - São Paulo - Brasil

alanestado@hotmail.com

\section{José Claudio Lopes}

Mestrando em Engenharia Mecânica

Universidade Estadual Paulista Júlio de Mesquita

Filho - Campus de Bauru

Departamento de Engenharia Mecânica

São Paulo - São Paulo - Brasil

jclaudio.lopes@hotmail.com

\author{
Luiz Eduardo de Angelo Sanchez \\ Professor-Adjunto \\ Universidade Estadual Paulista Júlio de Mesquita \\ Filho - Campus de Bauru \\ Departamento de Engenharia Mecânica \\ Bauru - São Paulo - Brasil \\ sanchez@feb.unesp.br
}

\author{
Hamilton Jose de Mello \\ Doutor \\ Universidade Estadual Paulista Júlio de Mesquita \\ Filho - Campus de Bauru \\ Departamento de Engenharia Mecânica \\ Bauru - São Paulo - Brasil \\ hamilton@feb.unesp.br \\ Paulo Roberto de Aguiar \\ Professor-Titular \\ Universidade Estadual Paulista Júlio de Mesquita \\ Filho - Campus de Bauru \\ Departamento de Engenharia Mecânica \\ Bauru - São Paulo - Brasil \\ aguiarpr@feb.unesp.br

\section{Eduardo Carlos Bianchi} \\ http://orcid.org/0000-0003-2675-4276 \\ Professor-Titular \\ Universidade Estadual Paulista Júlio de Mesquita \\ Filho - Campus de Bauru \\ Departamento de Engenharia Mecânica \\ Bauru - São Paulo - Brasil \\ bianchi@feb.unesp.br
}

Influence of water. in the MQL technique in the grinding of steel AISI 4340 using CBN wheels

\section{Abstract}

Usually, machining employs cooling methods to avoid high temperatures. In most cases, the cutting fluid is applied with high flow and low pressures. This technique consumes a large amount of cutting fluid that causes serious problems in the environment and in the health of the worker. An alternative to the conventional cooling method is the Minimum Quantity of Lubricant. The MQL attempts to minimize the consumption of cutting fluid, which this study is about, whereby the reduction provided by this MQL was $99.99 \%$. This technique consumes only the necessary quantity of cutting fluid to create a thin film of lubricant on the cutting surface grinding wheel. The MQL aerosol is injected with high pressure in the contact zone, efficiently lubricating the grinding process. However, the cooling effect of MQL is not enough to dissipate all heat produced during the grinding process. This study analyzes the improvement in the cooling effect caused by the addition of water in the MQL. The tests were done using different concentrations of cutting fluid in water, e.g. 1:0, 1:1, 1:3, 1:5 (oil:water). The experiment occurred on the external cylindrical plunge grinding with a vitrified cubic boron nitrite (CBN) grinding wheel, serving as the workpiece, the AISI 4340 quenched and tempered steel. The analyzed outputs were: surface roughness, roundness deviation, acoustic emission and vibration. . The results improved with the addition of water in the cutting fluid used in the MQL technique. The comparison with the MQL conditions showed that the best condition was the fluid with more water concentration.

keywords: cylindrical grinding machining, Minimum Quantity of Lubricant with water, CBN grinding wheel, steel AISI 4340. 


\section{Introduction}

A grinding process is employed to improve the surface finish and correct the workpiece geometry. To achieve these objectives the process has some particularities, e.g. the utilized cutting speeds are faster than the one used in the turning and milling, and the grinding wheel is composed of many cutting edges. Due to these intrinsic parameters, the grinding process has the highest specific energy among the machining processes, i.e. it consumes a significant quantity of energy to remove a small quantity of material. Therefore, the grinding process is executed in the last steps of manufacturing, removing only the necessary material to achieve the required parameters. A majority of the consumed energy is transformed into thermal energy, and consequently, the process temperature is elevated (Oliveira et al., 2012). Most part of the generated energy remains in the cutting zone, and impairs on: the grinding wheel properties and the workpiece specifications. When the abrasive grains are exposed to high temperatures, they lose their hardness, increasing grinding wheel wear (Oliveira et al., 2012). The grinding process occurs after the thermal treatments, to correct all distortions caused by the thermal treatment, therefore the temperature of the grinding process cannot be high enough to cause thermal damages in the material (workpiece burn, microstructural changes and micro cracking).

As noted, the grinding process takes place in high temperatures, which makes the cutting fluid indispensable. The cutting fluid enables the rise of the cutting speed and the feed rate, parameters that increase the productivity. According to Irani et al. (2005), the thermal damages are one of the main factors that restrain the grinding process efficiency. Accordingly, to remove further material in a lesser time, the machining engineers apply cutting fluid to decrease the process temperature, and, consequently the thermal damages on the workpiece are minimized.

The cutting fluid reduces the grinding temperature in two ways. The first one

\section{Experimental procedure}

The trials occurred in a cylindrical CNC grinding machine of SULMECÂNICA Company, RUAP $515 \mathrm{H}$ model, equipped with computer numeric control (CNC). Two CNC programs were is by directly extracting the heat out of the process by its refrigerant effect and the second one is maintaining the cutting efficiency of the grinding wheel, scaling down the friction by its lubricant effect, which reduces the grinding wheel wear and the specific energy. The second way provides a better control of the temperature than the first one. The secondary tasks of the cutting fluid are: flush away the chips from the contact area, remove the chips located in the pores of the abrasive tool and put a hold on the toxic gases produced in the process (Rowe, 2014).

Despite the benefits of the cutting fluid in the process, there are some disadvantages. The cutting fluid has high purchase and disposal costs. The inappropriate disposal of the cutting fluid is harmful to the environment, in addition, the cutting fluid is hazardous to the workers' health, e.g. the direct contact with the fluid may cause dermatological and respiratory diseases that can range from simple contact dermatitis to complicated cancer (Silva et al., 2013).

In the last decades, the studies to reduce or eliminate the use of cutting fluid increased. Despite the many advantages, the cutting fluid presents serious economic and environmental problems (Tawakoli et al., 2010). Thru these studies, the Minimum Quantity of Lubricant was developed. This method efficiently transports a small quantity of cutting fluid to the contact zone. Due to the drastic reduction of the cutting fluid used in the MQL, the technique avoids the serious problems caused by it.

This technique applies the aerosol precisely directed to the contact zone (grinding wheel-workpiece). The aerosol is generated by the atomization process, where the cutting fluid is dispersed in small droplets and is carried by the jet of air (Tawakoli et al., 2010). This mist flies directly to the grinding wheel cutting surface, creating a thin layer of lubricant that provides the necessary lubrication during the cut. The quantity of fluid used in the technique varies according to the machining process. Mainly, the quantity depends on the workpiece material, the machining process and the cutting tool (Walker, 2013). Despite the use of a small quantity of lubricant, the MQL has as advantage its efficiency in the aerodynamic barrier penetration, due to its high pressure (Marinescu et al., 2007).

The MQL technique has been attracting the attention of researchers, due to its potential to replace the conventional cooling method. The MQL system does not generate debris at the end of the process because it utilizes only a small quantity of fluid. The lubrication of the method is provided by the oil and the refrigeration by the compressed air (Silva et al., 2013).

The cooling effect of the MQL technique is provided only by the compressed air. As a result, in some cases, e.g. grinding, its cooling ability is not adequate (Yoshimura et al., 2005). Therefore, in a machining process with the high generation of heat, the utilization of MQL is challenging.

The addition of water in the MQL cutting fluid emerges as an attempt to improve its heat dissipation. Once the boiling point of water is easily exceeded while the process occurs, the water is convenient to improve the technique's cooling ability. Firstly, the water absorbs the heat to elevate its temperature until it achieves the boiling point, and then, the water evaporates. In this stage, the amount of absorbed heat is extremely high with finally, the water vapor dispersing in the atmosphere. As a result, the addition of water dissipates the exceeding heat away from the process (Yoshimura et al., 2005).

According to Yoshimura et al. (2005), the addition of water improved the results provided by the MQL in the machining process with defined cutting-edge geometry. Since the method has better a cooling capacity than the conventional MQL, the output parameters, e.g. dimensional and geometric accuracy, surface roughness and tool wear, are improved (Funes et al., 2012). utilized, one for machining workpieces and another for printing the grinding wheel profile.

The workpieces were made with AISI 4340 steel, machined in the ring- shape with an external diameter of 54 $\mathrm{mm}$, internal diameter of $30 \mathrm{~mm}$ and thickness of $4 \mathrm{~mm}$. Following, the workpieces were quenched and tempered by the Thermix Tratamentos Térmicos company, 
resulting in the hardness of $54 \pm 2$ HRc.

The tool was the CBN grinding wheel with vitrified bonded 14A1 type, the wheel dimensions were: external diameter of $350 \mathrm{~mm}$, internal diameter of $127 \mathrm{~mm}$, width of $15 \mathrm{~mm}$ and the abrasive layer thickness of $5 \mathrm{~mm}$. The tool was provided by Nikkon Ferramentas de Corte company with the specification SNB151 Q12 VR2.

The dressing process utilized the conglomerate dresser type, where the diamonds were displaced in the metallic body. The dressing depth was $0.002 \mathrm{~mm}$ in each pass, and the total removal was $0.120 \mathrm{~mm}$ in the grinding wheel diameter.

The conventional cooling system was composed of an 80-liter storage tank, a suction pump and two nozzles for the cutting fluid application. The cutting fluid was the emulsion of $3 \%$ of semi synthetic oil in water. The cutting fluid application was done using a flow of $17 \mathrm{~L} / \mathrm{min}$ and a pressure of $2.9 \times 10^{5} \mathrm{~Pa}$. The oil used in the emulsion was the semi synthetic soluble oil ME-1 from the QUIMATIC company.

\section{Results and discussion}

This section presents the results of the experimental procedure for each method of cooling. According to

\subsection{Surface roughness}

The surface roughness is an important output parameter, considering that

Figure 1

The arithmetic average of the surface roughness ( $\mathrm{Ra}$ ) for each cooling condition.

According to Silva et al. (2013), the surface roughness improves when the cooling method provides better cooling and lubricating effects. As can be seen in Figure 1, the lowest surface roughness was provided by the conventional method. According to Silva et al. (2013), it indicates that this condition provides the best cooling and lubricating effect among the analyzed conditions.

The interesting fact pointed out in Figure 1 is the improvement that the addition of water provided in the surface roughness. Silva et al. (2013) stated that the surface roughness is impaired when the workpiece suffers thermal expan-
The MQL equipment was: a compressor, a pressure regulator, a dosing valve of cutting fluid, and a nozzle projected to use in the grinding process. The dosing valve uses a dripping system for the oil supply, allowing the separation of the regulation of compressed air and the fluid flow. The equipment used in this research was the ITW Accu-lube 79053D, produced by the ITW Chemical Products Ltda.

The pressure in the MQL was $6.5 \times 10^{5} \mathrm{~Pa}$ and the cutting fluid flow was $100 \mathrm{ml} / \mathrm{h}$. The atomization of the cutting fluid occurs in the nozzle, based on the Venturi effect. The aerosol was directed to the grinding wheel near the contact zone.

The cutting fluid used in the MQL technique was the synthetic oil ME-2, made by the QUIMATIC company, diluted in water in the following proportions: 1:1, 1:3 and 1:5; also used was the pure synthetic oil.

All the input parameters were kept constant, except the cooling method. The cutting speed was $30 \mathrm{~m} / \mathrm{s}$, the radial feed rate was $0.50 \mathrm{~mm} / \mathrm{min}$, the workpiece speed was $0.58 \mathrm{~m} / \mathrm{s}$, the spark out time was 1.78 seconds for the grinding cycles and 3.56 seconds at the end of the experiment. In each experiment, there occurred 42 cycles, and in each cycle, two feeds of 100 micrometers and two spark outs occurred.

For the surface roughness measurement, used was the equipment Surtronic $3+$, from the Taylor Hobson Company. The surface roughness was measured perpendicularly to the grinding marks with a cut-off of $0.25 \mathrm{~mm}$ and the total path $(\ln )$ of $1.25 \mathrm{~mm}$, using the arithmetic average of the surface roughness profile $(\mathrm{Ra})$. To avoid errors, the surface roughness was measured at three points spaced at $120^{\circ}$.

The roundness deviation measurement was done using the gauge Tayrond $31 \mathrm{C}$ of Taylor Hobson company. Before each measurement, the workpiece was centralized by the two buttons of fine linear adjustment that moves the precision rotary table. For each workpiece, three initial contacts were done spaced at $120^{\circ}$.
Silva et al. (2013) when a new cooling method is tested the basic outputs for analyses of the new method are: sur- face roughness, roundness deviation, acoustic emission, vibration. this parameter interferes directly in the fatigue strength of the material. Figure 1 presents the results of the surface roughness and their standard deviations.

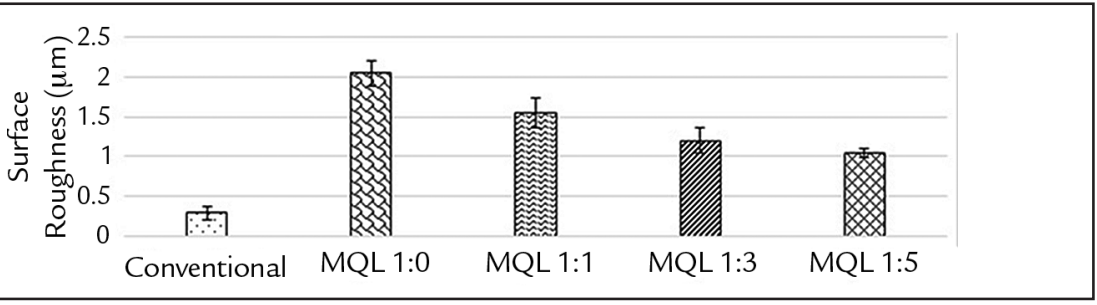

sion. Therefore, cooling capability of the method has to be enough to manage the generated heat. Despite its excellent lubrication, the MQL with pure oil did not present a cooling effect sufficient to dissipate all the generated heat, and consequently, the surface roughness was the worst of the five tested conditions. The addition of water in the MQL improved the cooling capability of the method, which resulted in lower surface roughness. The water plays an important role in the cooling effect improvement. It absorbs significant heat to become vapor. Thus the added water supports the heat management (Yoshimura et al., 2005).
Tawakoli et al. (2010) conclude in their research that oils with excessively high viscosity affect the efficiency of the process because the cutting forces are intensified. Another fact that impacted on the surface roughness improvement on the condition MQL 1:5 was the viscosity. The water presents a lower viscosity index than the oil, and consequently, as the proportion of water increased the viscosity decreased. An assumption is that the pure oil was too viscous for the process.

The fluid viscosity interferes with the MQL technique performance. The lower the viscosity, the better the at- 
omization, whereby the aerodynamics barrier penetration improves (Tawakoli et al., 2010). As expected, the addition of water in the MQL technique positively impacted the surface roughness, similarly to results of Yoshimura et al. (2005) where surface roughness improved in the milling process with the addition of wa- ter. Creating a balance between cooling and lubricating effects, water improved the cutting process that results in better output parameters.

\subsection{Roundness deviation}

Figure 2 presents the roundness deviation values of each cooling condition tested and their standard deviation.

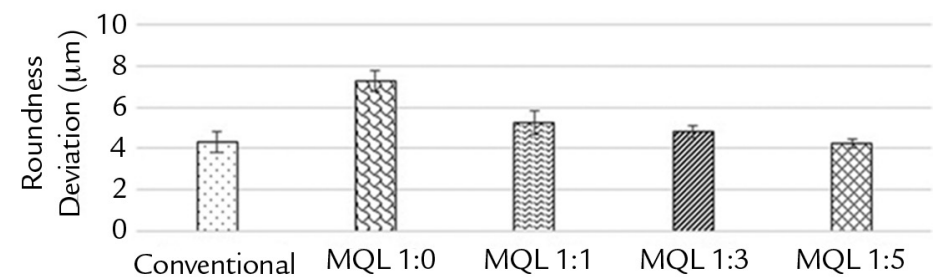

The best roundness deviation was provided by the MQL 1:5 condition, as presented in Figure 2. In addition, Figure 2 illustrates the tendency to decrease in roundness deviation when the proportion of water increases.

As previously mentioned, the precision of the process is compromised when the cooling of the process is not appropriate. As the proportion of water increases in the cutting fluid, better becomes the cooling effect of the MQL technique, avoiding the undesirable thermal expansion and reducing the workpiece roundness deviation. The improvement of the MQL cooling effect occurs because, according to Belentani et al. (2014), the water cooling capacity is two times better than the pure oil cooling capacity.

The high temperatures impair in

\subsection{Acoustic emission}

Oliveira et al. (2012) state that physics phenomenon, e.g. friction, plastic and elastic deformation, chip the ductility of the material, increasing it, which aggravates the material adherence in the grinding wheel cutting surface. It results in the serious problem in grinding called: wheel clogging. The phenomenon occurs when the chips lodge in the grinding wheel surface pores, whereby the availability of porosity to lodge new pores decreases, increasing the cutting forces and power required. In addition, the heat generated in the process is going to be greater (Oliveira et al., 2012). According to Belentani et al. (2014), the fluid viscosity used in the MQL technique is directly related to the capacity to remove the chips from the cutting zone (between the grinding wheel cutting surface and the workpiece). Summarizing, the efficiency of removing the chips increases, when the viscosity decreases, which results in

removal, are responsible for generating signals of acoustic emission. Figure 3 presents the acoustic emission for each

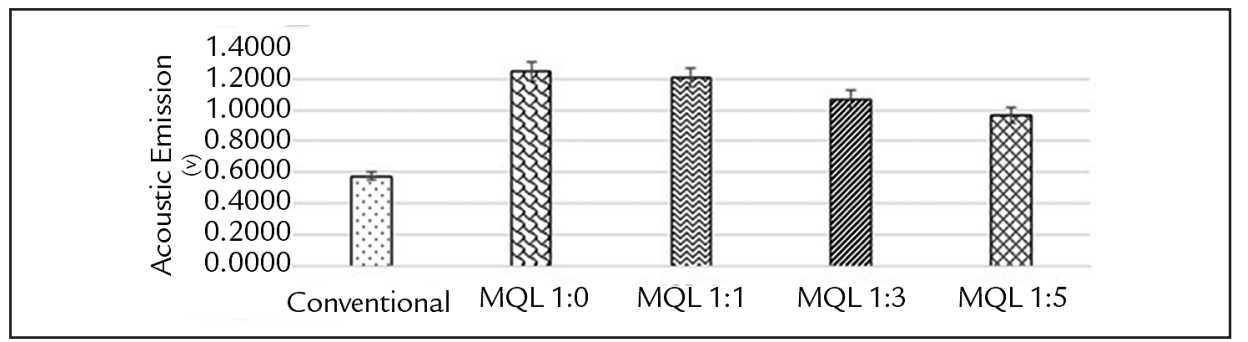

According to Figure 3, the conventional condition provided the lowest emission acoustic result of the tested conditions. Furthermore, it is possible to observe in Figure 3 that the values for acoustic emission decrease with the addition of water.

The MQL has difficulty to completely remove the chips produced in the grinding process, causing the clogging phenomena. The adhered chips scratch against the workpiece and generate acoustic emissions (Oliveira et al., 2012). The addition of water rises the cooling effect of the MQL technique, maintaining the temperatures lower than without water (Yoshimura et al., 2005). As a result, the ductility of the material does not reduce,
Figure 2

The average of roundness deviation measurement for each cooling condition.

the mitigation of the occurrence of the clogging phenomena. In fact, the addition of water in the cutting fluid used in the MQL technique has two functions in the clogging prevention: it decreases the process temperature and it improves the capacity of removing the chips from the contact zone. Therefore, the roundness results were positively influenced by the addition of water in the cutting fluid used in the MQL technique.

Analyzing the roundness deviation results, the viability of MQL becomes clear, indicating that it is possible to obtain satisfactory results using a minimal amount of lubricant. As can be observed in Silva's et al. (2013) research, it is possible to achieve the same result level of conventional cooling using the MQL technique with small flows of cutting fluid $(<80 \mathrm{ml} / \mathrm{h})$.

cooling condition tested and their standard deviation.

Figure 3

The average of acoustic emission for each cooling condition.

and, consequently, it ameliorates the clogging phenomena. Thus, the addition of water in the MQL technique reduces the occurrence of the clogging phenomena. This assumption is made based on Figure 3 and the statements by Oliveira et al. (2012) and Yoshimura et al. (2005). Figure 4 shows the chips returning to the contact zone. 


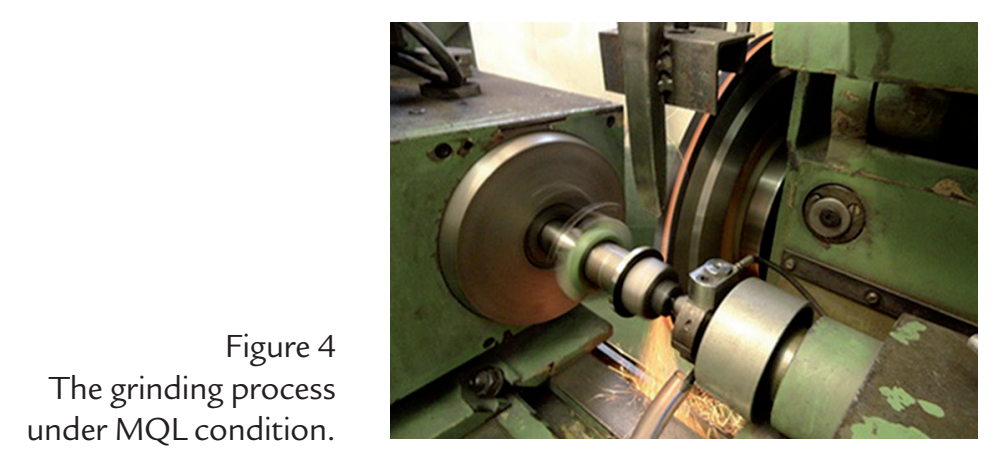

As presented in Figure 4, the chips return to the contact zone when the MQL is used, hence they scratch the workpiece surface and increase the acoustic emission whereby the surface quality becomes worse. Acoustic emission evaluation showed an unexpected propriety for the addition of water in MQL technique, the minimization of wheel clogging by its cooling improvement. Also, the water balances the cooling and lubricating effects, creating a better proportion between these two effects to minimize physical phenomena (e.g. friction, elastic deformation and chip removal) (Oliveira et al., 2012). Evidencing that an ecofriendly technique, addition of water, is capable to minimize the clogging phenomenon; a drastic problem in grinding process.

\subsection{Vibration}

Figure 5 presents the average of the system values captured during the trials.

Figure 5

The average of the system vibration for each cooling condition.

According to Rowe (2014), the system vibration impairs the process accuracy and the surface quality. The same tendency presented in Figure 5 is presented in Figures 1 and 2, and shows that the system vibration is connected with the surface roughness and the

\section{Conclusions}

By the presented results in the previous section, it is possible to conclude:

- The addition of water improved the cooling effect of the MQL technique, the highest proportion of water resulted in best results among the tested conditions.

- The clogging phenomena occurrence decrease with the addition of water, the rise of the cooling effect of the MQL

\section{Acknowledgements}

Sincere thanks to FAPESP (State of São Paulo Research Foundation - Process Number 2015/09868-9) for the support- and the lower viscosity of the fluid are responsible for this.

- The mist generation rate machining under the conventional condition was higher than under the MQL conditions. Also, the cutting fluid spread all over the machine with the use of conventional condition, while on the other hand, the $\mathrm{MQL}$ debris remained located below the cutting zone.

ing financially this work and the companies ITW Chemical Products, Quimatic Tapmatic and Nikkon Ferramentas de
- The results generated in the machining under the MQL conditions were not comparable with the ones produced by the conventional conditions, however, the environmental impact of the MQL technique is far less than the conventional condition.

- In all the analyzed conditions, the water's addition improved the grinding performance.

Corte Ltda by the material support given this research.

\section{References}

ANDERSON, D., WARKENTIN, A., BAUER, R. Experimental validation of numerical thermal models for dry grinding. Journal of Materials Processing Technology, 
v. 204, p. 269-278, 2007.

BELENTANI, R. M., FUNES, H. J., CANARIN, R. C., DINIZ, A. E., HASSUI, A., AGUIAR, P. R., BIANCHI, E. C. Utilization of minimum quantity lubrication (MQL) with water in CBN grinding of steel. Materials Research, v. 17, p. 88-96, 2014.

IRANI, R. A., BAUER, R. J., WARKENTIN, A. A review of cutting fluid application in the grinding process. International Journal of Machine Tools \&Manufacture, v. 45, p. $1696-1705,2005$.

FUNES, HAMILTON JUNIOR. Utilização da técnica da mínima quantidade de lubrificante (MQL) com adição de água no processo de retificação cilíndrica externa de aços endurecidos com rebolo CBN. Bauru, SP: Programa de Pós-Graduação em Ciência e Tecnologia de Materiais, Universidade Estadual Paulista, 2012. (Dissertação de Mestrado).

MARINESCU, I. D., HITCHINER, M., UHLMANN, E., ROWE, W. B., INASAKI, I. Handbook of machining with grinding wheels. USA: CRC Press, Taylor \& Francis Group, 2007.

NASCIMENTO, W. R., YAMAMOTO, A. A., MELLO, H. J., CANARIM, R. C., AGUIAR, P. R., BIANCHI, E. C. A study of the viability of minimum quantity lubrication with water in grinding of ceramics using a hybrid-bonded diamond wheel. Journal of Engineering Manufacture, DOI: 10.1177/0954405415579016, 2015.

OLIVEIRA, D. J., GUERMANDI, L. G., BIANCHI, E. C., DINIZ, A. E., AGUIAR, P. R., CANARIN, R. C. Improving minimum quantity lubrication in CBN grinding using compressed air wheel cleaning. Journal of Materials Processing Technology, v. 212, p. 2559-2568, 2012.

ROWE, W. B. Principles of modern grinding technology. Oxford. (2. ed.): Elsevier, 2014.

RUZZI, R. S., BELENTANI, R. M., MELLO, H. J., CANARIM, R. C., DORIANA D'ADDONA, DINIZ, A. E., AGUIAR, P. R., BIANCHI, E.C. MQL with water in cylindrical plunge grinding of hardened steels using CBN wheels, with and without wheel cleaning by compressed air. International Journal of Advanced Manufacturing Technology, 2016.

SILVA, L. R., CORRÊA, E. C. S., BRANDÃO, J. R., ÁVILA, R. F. Environmentally friendly manufacturing: behavior analysis of minimum quantity of lubricant - MQL in grinding process. Journal of Cleaner Production, DOI: 10.1016/j.jclepro.2013.01.033, 2013.

TAWAKOLI, T., HADDAD, M. J., SADEGHI, M. H. Investigation on minimum quantity lubricant- MQL grinding of 100Cr6 hardened steel using different abrasive and coolant-lubricant types. International Journal of Machine Tools \& Manufacture, v. 50, p.698-708, 2010.

WALKER, T. The MQL handbook, a guide to machining with minimum quantity lubrication, Unist, Inc., v.1.0.3, 2013.

YOSHIMURA, H., ITOIGAWA, F., NAKAMURA, T., NIWA, K., Development of nozzle system for oil-on-water droplet metalworking fluid and its application on practical production line. JSME International Journal, v. 48, n. 4, p. 723-729, 2005.

Received: 11 October 2017 - Accepted: 8 February 2018. 